\title{
MULTIMEDIA ANIMASI MEKANISME KOMPONEN PNEUMATIK
}

\author{
Purnawan $^{1}$, Haryadi ${ }^{1}$, Dedi Rohendi ${ }^{1}$, Detri Fewana ${ }^{1}$, Sudaryono $^{2}$ \\ ${ }^{1}$ Jurusan Pendidikan Teknik Mesin FPTK UPI \\ ${ }^{2}$ SMK Merdeka Bandung \\ Jl. Dr. Setiabudhi 207 Bandung \\ E-mail : purnawanupi@yahoo.co.id
}

\begin{abstract}
Abstrak. Tujuan penelitian ini adalah untuk mengetahui perbedaan peningkatan hasil belajar siswa, antara siswa yang mengunakan media animasi dengan siswa yang menggunakan media power point sebagai media tayang. Seting pembelajaran dilakukan pada mata pelajaran DKTM khususnya pada kompetensi dasar mengetahui simbol dan cara kerja komponen pneumatik. Penelitian menggunakan metode quasi eksperimen dengan posttest only control group design. Data diperoleh melalui tes hasil belajar terhadap 80 siswa yang terdiri atas 44 siswa pada kelas kontrol dan 36 siswa pada kelas eksperimen. Hasil penelitian menunjukkan rata-rata hasil belajar siswa pada kelas eksperimen sebesar 57,48, lebih tinggi dibanding kelas kontrol sebesar 39,68. Pengujian hipotesis menunjukkan penggunaan media animasi mekanisme komponen pneumatik hasil pengembangan sebagai media tayang memberikan hasil belajar yang lebih baik dibandingkan dengan menggunakan power point.
\end{abstract}

Kata kunci : multimedia animasi, mekanisme pneumatik, hasil belajar.

\begin{abstract}
This study investigates the difference of student's learning outcome improvement between students who use animation and those who use power point program as presentation media. The study was carried out in the DKTM subject, particularly for the basic competence of understanding the symbols and working mechanism of pneumatic components. The research employed quasi-experimental method with post-test only control group design. Data was obtained from a final test given to 80 students, consisting of 44 students of the control class and 36 students of the experimental class. The result shows that the experimental class has a higher grade average $(57,48)$ than the control class $(39,68)$. The hypothesis examination shows that the use of animation to present penumatic components' mechanism improves students' learning outcome if compared to the use of the power point program.
\end{abstract}

Keywords: animation multimedia, pneumatics mechanisms, learning outcomes.

\section{PENDAHULUAN}

Teknologi pengelolaan udara terkompresi sebagai media kerja, sebenarnya telah lama diketahui oleh manusia, namun baru mulai berkembang dan diaplikasikan di industri sekitar tahun 1950 (Meixner,H 1978 : 9). Seiring dengan tuntutan peningkatan produktivitas dan kualitas hasil kerja, pemanfaatan udara 
terkompresi mengalami perkembangan yang pesat, terutama untuk tujuan otomasi yang dikenal dengan sistem pneumatik.

Pneumatik sebagai sistem dibangun atas dua konsep utama yaitu konsep stuktur sistem dan konsep mekanisme komponen. Konsep struktur sistem menjelaskan bagaimana siklus fluida berproses dan membangkitkan sinyal sehingga membentuk sebuah sistem kerja, sedangkan konsep mekanisme komponen menjelaskan sifat-sifat komponen dalam sebuah sistem tersebut yang meliputi; prinsip kerja, metode aktuasi dan pengembaliannya, jumlah posisi kontak yang mungkin terjadi, jumlah saluran input, jumlah saluran output dan sebagainya. Penjelasan konsep-konsep tersebut direpresentasikan dalam simbolsimbol verbal yang terstandarisasi dalam DIN ISO 1219 dan DIN ISO 5599 (P.Croser, 1994:34).

Kesulitan memahami konsep yang abstrak, komplek, dan dinamik merupakan permasalahan dalam pembelajaran sistem pneumatik. Berdasarkan hasil penelitian (Purnawan:2006), model teoritis berupa simbol-simbol verbal maupun media/alat bantu pembelajaran yang tersedia, tidak cukup representatif untuk dapat menjelaskan konsep sistem pneumatik secara realistis, sehingga kemungkinan tidak terjangkau (inaccessible) oleh peserta didik yang efeknya kurang menimbulkan pengalaman belajar.

Berdasar paparan tersebut, maka diperlukan media pembelajaran yang tidak hanya dalam tataran teoritis, tetapi media yang praktis, ekonomis, dan mudah dijangkau (accessible) yang mampu mengkonsolidasikan konsep sistem pneumatik. Upaya memenuhi kriteria accessible dapat ditempuh dengan memanipulasi model teoritis (verbal / simbol) menjadi model realistis agar mudah diajarkan (teachable). Penelitian sebelumnya telah menghasilkan media belajar berupa media animasi mekanisme komponen-komponen pneumatik dengan menggunakan program macromedia flash 8. Animasi mekanisme komponen mencakup lima elemen dasar penumatik, yaitu : elemen pemroduksi media meliputi kompresor 1 stage, air dryer 3 metode, dan air service unit, elemen pembangkit sinyal meliputi Directional Control Valve (DCV) 2/2 NC G-SR dan DCV 3/2 G-SR, elemen pemroses sinyal meliputi katup logika AND dan OR serta 
Delay Time Valve (DTV), elemen pengontrol akhir meliputi DCV 4/2 G-SR, DCV 5/2 DP-DM, dan one way Flow Control Valve (FCV), serta elemen kerja meliputi single dan double acting cylinder.

Pada penelitian ini dilakukan pengujian terhadap produk media animasi hasil pengembangan sebagai media pembelajaran. Pengujian dilakukan dengan menerapkan media animasi pada proses pembelajaran simbol dan cara kerja komponen pneumatik pada sebuah kelas lalu membandingkan hasil belajarnya dengan kelas lain yang menggunakan media power point. Perbedaan hasil belajar antara kedua kelas ini, menjadi indikator efektifitas media animasi yang dikembangkan. Penerapan media animasi yang dikembangkan ini diharapkan akan mampu meningkatkan kualitas proses dan hasil belajar siswa, sehingga secara langsung akan mampu meningkatkan pencapaian kompetensi siswa.

\section{METODE PENELITIAN}

Penelitian ini merupakan bagian dari penelitian pengembangan yang menggunakan pendekatan research and development (R\&D). Khusus penelitian ini menggunakan metode quasi eksperimen dengan posttest only control group design. Pada kelas eksperimen dalam kegiatan belajar mengajarnya (KBM) inti menggunakan media animasi mekanisme komponen pneumatik hasil pengembangan, sementara itu pada kelas kontrol menggunakan media power point yang dibuat oleh guru pengampu. Secara skematis desain penelitian ditunjukkan pada gambar 1.

\begin{tabular}{|l|l|c|}
\hline $\begin{array}{l}\text { Kelas } \\
\text { kontrol }\end{array}$ & $\begin{array}{l}\text { Pembelajaran simbol dan } \\
\text { mekanisme komponen pneumatik } \\
\text { dengan bantuan media power point }\end{array}$ & $\begin{array}{c}\text { Post } \\
\text { test }\end{array}$ \\
\cline { 1 - 1 } $\begin{array}{l}\text { Kelas } \\
\text { eksperimen }\end{array}$ & $\begin{array}{l}\text { Pembelajaran simbol dan } \\
\text { mekanisme komponen pneumatik } \\
\text { dengan bantuan media animasi flash }\end{array}$ & $\begin{array}{c}\text { Post } \\
\text { test }\end{array}$
\end{tabular}

Gambar 1. Desain penelitian 
Media animasi mekanisme komponen pneumatik yang dihasilkan pada tahap sebelumnya, dibuat dengan menggunakan program " macro media flash player versi 8". Media animasi yang telah selesai dibuat kemudian disimpan dalam compact disk (CD). Sebelum kegiatan belajar mengajar berlangsung, file pada CD tersebut telah dicopy dalam komputer guru. Media power point yang dibuat oleh guru mata pelajaran, menggunakan program MS Office. Program ini telah disimpan dalam komputer guru. Kedua media tersebut diperlakukan sebagai media tayang, sehingga hanya berfungsi sebagai alat bantu pembelajaran, sementara itu sumber informasi utama masih berupa penjelasan guru yang bersifat lisan. Pengajaran pada kedua kelompok dilakukan oleh guru yang sama. Perbedaan tampilan kedua media yang digunakan dalam penelitian ini ditunjukkan pada gambar 2.

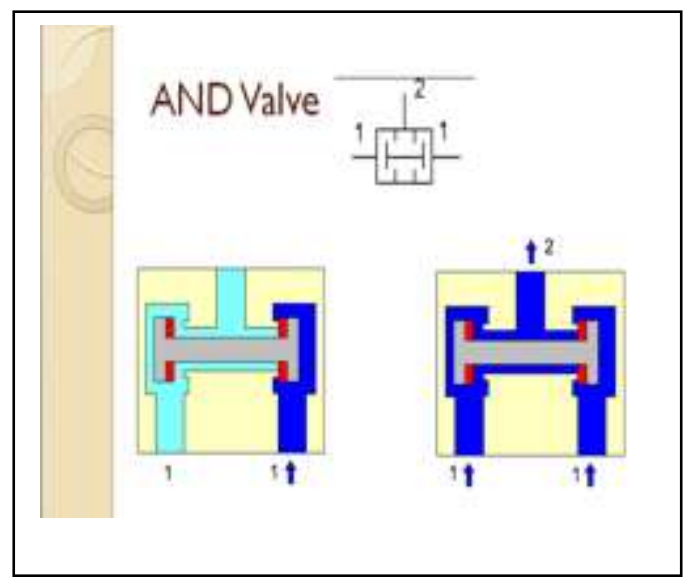

(a)

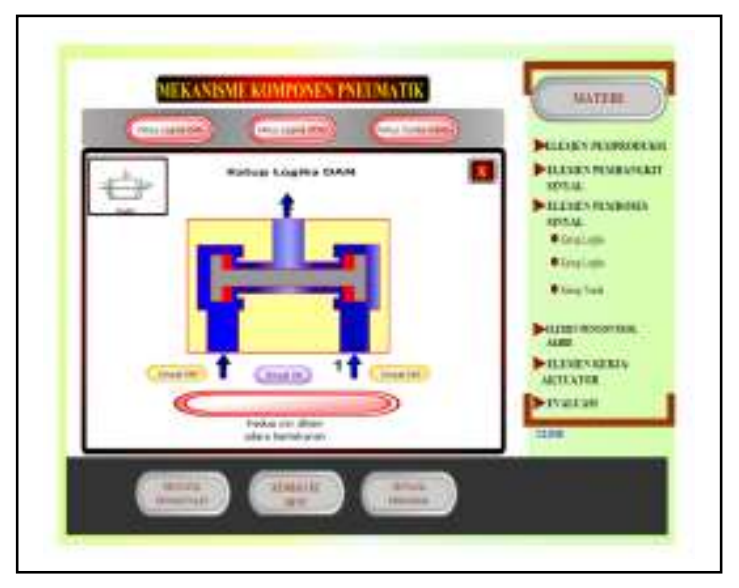

(b)

Gambar 2. Contoh tampilan media tayang (a) power point (b) animasi flash

Setelah kegiatan penyampaian materi selesai, dilanjutkan dengan pemberian post test terhadap masing-masing kelompok. Post tes ini diberikan kepada 80 siswa yang terdiri atas 44 siswa pada kelas kontrol dan 36 siswa pada kelas eksperimen. Test yang dilakukan masih menggunakan paper base berupa test objektif pilihan ganda dengan lima pilihan yang telah dijustifikasi oleh guru mata pelajaran DKTM. Data hasil post test lalu diolah dan dianailis untuk menjawab hipotesis yang diajukan. Analisis data difokuskan dengan melihat perbedaan hasil belajar antara kelas kontrol dengan kelas eksperimen. 


\section{HASIL DAN PEMBAHASAN}

Berdasarkan Rencana Pelaksanaan Pembelajaran (RPP) yang disusun, KBM pada kompetensi dasar "mempelajari gambar simbol dan cara kerja komponen pneumatik" ini dibagi dalam 3 sekuen, yaitu Pra KBM, KBM inti, dan penutup. KBM inti terdiri atas 3 tahapan, yaitu eksplorasi, elaborasi, dan konfirmasi. Pada tahap eksplorasi inilah setalah guru mengetahui pengetahuan awal siswa tentang materi secara umum, dilanjutkan penyampaian materi dengan menggunakan bantuan media. Dalam kegiatan penutup setelah kesimpulan disampaikan kemudian dilakukan evaluasi berupa tes hasil belajar.

Hasil pengamatan pada pelaksanaan KBM, dapat dipaparkan beberapa hal menyangkut persiapan, kegiatan inti, dan akhir kegiatan. Pada tahap persiapan teridentifikasi bahwa persiapan sarana belum sepenuhnya mendukung untuk terselenggaranya kegiatan pembelajaran dengan menggunakan multi media. Untuk mempersiapkan peralatan dibutuhkan waktu yang relatif lama, sehingga mengurangi alokasi waktu untuk KBM inti. Pada pelaksanaan KBM inti, guru masih belum sepenuhnya berpatokan pada rencana pembelajaran yang telah disusun sebelumnya. Juga terlihat guru masih kurang menguasai materi yang disampaikannya, sehingga masih kurang lancar dalam menyampaikan isi materi kepada siswa. Namun demikian terlihat adanya kesungguhan sebagaian besar siswa memperhatikan penjelasan guru dan memperhatikan tayangan, meskipun komunikasi masih dominan dalam satu arah.

Pada pelaksanaan KBM inti, penggunaan kedua media (media power point dan media animasi flash) adalah sebagai media tayang. Penyampaian materi masih dilakukan oleh guru secara oral dengan dibantu oleh penggunaan media. Teramati bahwa guru belum mengusai betul cara-cara mengoperasikan tombol navigasi terutama pada penerapan media animasi. Hal ini, menjadi catatan bagi peneliti tentang perlunya melatih guru dalam mengoperasikan media animasi sebelum guru melaksanakan proses pembelajaran.

Setelah kegiatan inti, yaitu penyampaian materi tentang simbol dan mekanisme komponen pneumatik selesai, dilanjutkan dengan pemberian tes kepada masing-masing kelas. Meskipun dari hasil pengamatan pada proses 
pembelajaran pada kedua kelas masih terlihat kekurangan, namun secara umum proses pembelajaran telah sesuai dengan rencana pembelajaran yang dibuat.

Sesuai dengan tujuan penelitian dan desain yang telah dikemukanan sebelumnya, maka inti penelitian ini adalah melihat perbedaan hasil belajar antara kelas eksperimen dengan kelas kontrol. Data tes hasil belajar tersebut ditunjukkan pada tabel 1.

Tabel 1. Data hasil tes pada kedua kelas

\begin{tabular}{cccccc}
\hline Kelas & $\begin{array}{c}\text { Jumlah } \\
\text { siswa }\end{array}$ & $\begin{array}{c}\text { Skor } \\
\text { Tertinggi }\end{array}$ & $\begin{array}{c}\text { Skor } \\
\text { Terendah }\end{array}$ & $\begin{array}{c}\text { Rata- } \\
\text { rata }\end{array}$ & $\begin{array}{c}\text { Varians } \\
\left(\mathrm{S}^{2}\right)\end{array}$ \\
\hline Eksperimen & 36 & 84,61 & 23,07 & 57,48 & 275,52 \\
Kontrol & 44 & 61,53 & 15,38 & 39,68 & 195,25 \\
\hline
\end{tabular}

Pada tabel 1 terlihat bahwa, rata-rata hasil belajar siswa pada kelas eksperimen, yaitu kelas yang menggunakan media animasi flash hasil pengembangan lebih tinggi dibandingkan dengan kelas kontrol. Namun demikian rata-rata hasil belajar pada kedua kelas tersebut belum mencapai Kriteria Ketuntasan Minimal (KKM) sebesar 70. Sementara itu distribusi data tes hasil belajar siswa berdasarkan kriteria penilaian sekolah sebagaimana ditunjukkan pada tabel 2.

Tabel 2. Distribusi tes hasil belajar

\begin{tabular}{|c|c|c|c|c|c|c|c|}
\hline \multirow{2}{*}{$\begin{array}{c}\text { Rentang } \\
\text { Skor }\end{array}$} & \multirow{2}{*}{ Nilai } & \multicolumn{2}{|c|}{ Kelas Kontrol } & \multicolumn{2}{|c|}{ Kelas Eksperimen } & \multicolumn{2}{|c|}{ Keseluruhan } \\
\hline & & Jumlah & $\%$ & Jumlah & $\%$ & Jumlah & $\%$ \\
\hline$>80$ & A & 0 & 0 & 3 & 8,3 & 3 & 3,75 \\
\hline $70-79$ & B & 0 & 0 & 2 & 5,6 & 2 & 2,50 \\
\hline $60-69$ & $\mathrm{C}$ & 2 & 4,5 & 16 & 44,4 & 18 & 22,50 \\
\hline $50-59$ & $\mathrm{D}$ & 12 & 27,3 & 5 & 13,9 & 16 & 20,00 \\
\hline$<50$ & $\mathrm{E}$ & 30 & 68,2 & 10 & 27,8 & 40 & 50,00 \\
\hline & Jumla & 44 & 100 & 36 & 100 & 80 & 100 \\
\hline
\end{tabular}

Pada tabel 2 terlihat bahwa setengah jumlah siswa secara keseluruhan masuk dalam kategori gagal. Pada kelas kontrol bahkan kurang dari setengahnya yang lulus itupun dengan kriteria $\mathrm{C}$ dan $\mathrm{D}$, sedangkan sebagain besar masuk dalam kriteria gagal (E). Pada kelas eksperimen distribusi lebih merata, terlihat sebagian besar siswa lulus dengan frekwensi terbanyak pada kriteria C namun 
masih terdapat lebih dari seperempat siswa yang belum lulus. Data tersebut menjadi indikasi bahwa pada kelas eksperimen yang menggunakan media animasi flash kualitas pembelajarannya lebih baik dibandingkan pada kelas kontrol yang mengunakan media tayang power point. Bila mengacu pada syarat kelulusan berdasarkan standart kompetensi maka hanya 5 orang $(6,25 \%)$ yang dapat dinyatakan lulus. Hal ini menjadi indikasi proses pembelajaran secara keseluruhan masih dipandang kurang efektif.

Pengujian hipotesis menunjukkan bahwa $\mathrm{H}_{0}$ ditolak dan $\mathrm{H}_{\mathrm{A}}$ diterima. Hal ini menunjukkan bahwa penggunaan media animasi mekanisme komponen pneumatik sebagai media tayang memberikan hasil belajar yang lebih baik dibandingkan dengan menggunakan power point. Dengan demikian media animasi mekanisme komponen pneumatik yang telah dibuat dianggap lebih baik dan layak untuk digunakan sebagai media/alat bantu belajar mengenai simbol dan mekanisme komponen-komponen pneumatik.

Secara umum hasil penelitian ini sejalan dengan hasil penelitian-penelitian sebelumnya yakni pembelajaran dengan menggunakan bantuan komputer mampu meningkatkan hasil belajar siswa (Nurdin : 2009, Rahayu : 2011). Pemanfaatan komputer sebagai alat bantu dalam proses pembelajaran perlu untuk terus dilakukan agar kualitas proses dan hasil belajar semakin menigkat.

\section{KESIMPULAN}

Rata-rata hasil belajar siswa pada kelas eksperimen lebih tinggi dibandingkan pada kelas kontrol. Penggunaan media animasi mekanisme komponen pneumatik sebagai media tayang memberikan hasil belajar yang lebih baik dibandingkan dengan menggunakan power point.

Disarankan agar media animasi mekanisme komponen pneumatik dikembangkan lagi dan diujicobakan secara lebih luas dengan model pembelajaran individual. Model pembelajaran ini diharapkan akan memberikan kesempatan yang lebih besar kepada siswa untuk belajar sesuai dengan akselerasinya masing-masing. Selain itu validitas media yang dikembangkan akan lebih terjamin lagi. 


\section{DAFTAR PUSTAKA}

H. Meixner. (1979). Introduction to Pneumatic, D-7300 Esslingen : Festo Didactic

Nurdin Ibrahim, (2009). Pengaruh Pembelajaran Berbantuan Komputer terhadap Hasil Belajar, Jurnal Pendidikan dan Kebudayaan Vol. 15 No.1, Januari 2009 hal $108-125$.

P. Croser (1994). Pneumatic Basic Level TP 101, D-7300 Esslingen : Festo Didactic

Purnawan. (2006). Desain Model Komponen Pneumatik untuk Media Pembelajaran Mekanisme Komponen Pneumatik, Jurnal INVOTEC Volume III, No. 9, Agustus 2006 : 116 - 124.

Rahayu Kariadinata,(2011). Penerapan Pembelajaran Berbasis Teknologi Multimedia, EDUCARE: Jurnal Pendidikan dan Budaya Generated: 5 August, 2011, 08:01 